\title{
Energy-Saving Night Temperature Regime for Satsuma Mandarins (Citrus unshiu Marc.) Grown in a Plastic House with Heating. III. Application of Different Night Temperature Patterns
}

\author{
Taku YAno ${ }^{1,2}$, Kimiaki Matsubara ${ }^{1}$, Moe ShimookA ${ }^{1}$, Akira TAmanol ${ }^{1}$, Minoru NARAhara ${ }^{1}$, \\ Masatoshi KawAno ${ }^{1}$, Shunichiro Ito ${ }^{1}$, Shuji Setoyama ${ }^{2}$, Eriko Yasunaga ${ }^{3}$, Takuya ARAKI ${ }^{4}$ and Masaharu KitAnO ${ }^{2}$ \\ 'Fruit Tree Group, Oita Prefectural Agriculture, Forestry and Fisheries Research Center, Kunisaki, Oita 873-0511, Japan \\ ${ }^{2}$ Faculty of Agriculture, Kyushu University, Fukuoka 812-0581, Japan \\ ${ }_{3}^{3}$ Institute for Sustainable Agro-ecosystem Services, the University of Tokyo, Tokyo 188-0002, Japan \\ ${ }^{4}$ Faculty of Agriculture, Ehime University, Matsuyama, Ehime 790-8566, Japan
}

(Received January 28, 2014; Accepted June 17, 2014)

\begin{abstract}
In order to control nighttime temperatures with energy saving, how different night temperature regimes affected on the fruit growth, quality and ${ }^{13} \mathrm{C}$ allocation from leaf to fruit were researched by both the partial heating and whole tree heating. One type, altering time of nighttime heating, the end of day (EOD) -heating, middle of night (MON) -heating, and predawn (Pd) -heating were applied. The EOD-heating temporally activated the fruit growth and accelerated the ${ }^{13} \mathrm{C}$ allocation from leaf to fruit through short term (hours) researches by the partial heating, however, comparing to the conventional heating as $20^{\circ} \mathrm{C}$ constant in nighttime by the whole tree heating during 60-90 days after full bloom (DAFB), no superiority was observed in both the fruit volume increase and fruit quality, and the MON-heating showed the depression of fruit growth. Another type of a regime determined by daily integrated solar radiation, comparing to the conventional heating as $17^{\circ} \mathrm{C}$ constant in nighttime during $78-120 \mathrm{DAFB}$, no superiority was observed in the fruit quality. Nighttime ${ }^{13} \mathrm{C}$ allocation from the leaf to fruit was detected at 90 DAFB, though was hardly detected at all at 120 DAFB regardless of night temperatures as high as $25^{\circ} \mathrm{C}$ at both days.
\end{abstract}

Keywords : ${ }^{13} \mathrm{C}$ partitioning, partial heating, temperature regime

\section{INTRODUCTION}

In the last 40 years, several types of energy-saving temperature regimes based on plant physiology have been reported in horticultural crops. For example, in tomatoes, a multi-variable control system of environmental factors, whereby night temperature was determined by solar radiation accumulated daily, has been proposed (Yoshioka and Takahashi, 1981). However, in fruit trees, few reports have shown the effectiveness of such control systems.

In horticultural crops, the effect of nighttime temperature on plant growth has no general agreement yet. For example, dry matter distribution in tomatoes is not significantly affected by the temperature $\left(18^{-}-24^{\circ} \mathrm{C}\right) \mathrm{di}-$ rectly (Heuvelink, 1995). In lettuce and chrysanthemums, the integrated effects of different night temperature regimes on plant growth were negligible (Langhans et al., 1981). In young cucumbers, fluctuating temperatures were shown to have a positive effect compared to constant temperatures (Challa and Brouwer, 1985). For establishing energysaving temperature regime in tree fruits, it is important to clarify whether these results apply to the tree fruits such as Satsuma mandarin, and the much important study is to seek general agreement in horticultural crops.
Recently, a new night temperature regime known as EOD (End Of Day)-heating has been used in the growing flowers (Douzono et al., 2010, 2012). The EOD-heating is to promote flowering under an energy-saving night temperature condition. The character of this new EOD-heating is to raise the night temperature over an adequate temperature range for several hours at the beginning of night and to leave the night temperature under an adequate temperature range for residual hours at midnight and predawn, which is in contrast to the conventional temperature regimes that always maintain nighttime temperature in adequate ranges (Parups, 1978; Bonaminio and Larson, 1980). In Satsuma mandarins grown in a plastic house with heating, we tested the effect of EOD-heating on flowering and found that full blooming was delayed a few days under an EOD-heating regime (not published) compared to the conventional temperature regime. However, the effect of EOD-heating on the fruit growth and quality has yet to be shown.

Satsuma mandarin in a plastic house with heating suit for the tracer experiment using ${ }^{13} \mathrm{C}$, because some uniformed characters can be pointed, for example, the summer shoot germination, leaf age of the shoot, flowing, and fruit stage. These characters have an advantage for modeling a source-sink balance with assuming a fruit bearing shoot as a source-sink unit. And more, the larger number of units

Corresponding author: Takuya Araki, fax: +81-89-946-9526, e-mail : araki@agr.ehime-u.ac.jp 
can be available from a tree as the tree matured, and the partial heating or cooling the units seems to be quite effective for clarifying the ${ }^{13} \mathrm{C}$ allocation to the fruits in the source-sink unit and fruit growth, particularly in the shortterm (over a period of hours) changes in the night temperature.

Former studies have shown that high-quality fruit production in Satsuma mandarin is based on adequate temperature control, specifically maintaining the temperature between 20 and $25^{\circ} \mathrm{C}$ during the pre-harvest growth period (Kurihara, 1969, 1971; Utsunomiya et al., 1982; Inoue and Chien, 1988). In the early stage of fruit growth, Satsuma mandarins grown in a plastic house with heating should be grown in temperatures maintained around $25^{\circ} \mathrm{C}$ in the daytime and $20^{-} 23^{\circ} \mathrm{C}$ at night for active fruit growth (Yano et al., 2014). In addition, for the production of commercially attractive fruits of desired color, the temperature should not be lower than $16^{-}-17^{\circ} \mathrm{C}$ to enable the generation of carotenoids in the fruits' rind.

In this study, we considered maintaining the temperature $20^{\circ} \mathrm{C}$ as adequate night temperature for fruit growth and quality in Satsuma mandarins grown in a plastic house with heating and tried to clarify the effect of two types of energy-saving night temperature regimes on the fruit growth and quality. One type was the altering time of nighttime heating which including EOD-heating, and another was nighttime temperature regime determined by daily integrated solar radiation. The temporal fruit growth and ${ }^{13} \mathrm{C}$ allocation from leaf to fruit were researched through short-term (hours) method by partial heating system at each source-sink unit, and the integrated fruit growth, xylem water potential, and fruit quality were through general long-term (days) research method, respectively.

\section{MATERIALS AND METHODS}

\section{Partial heating system}

In order to clarify the effect of night temperature on fruit growth and ${ }^{13} \mathrm{C}$ allocation to the fruits in a source-sink unit, the partial heating system was constructed as Fig. 1. The system consisted of an electric blower (BN2.5 $70 \mathrm{~mm}$, YOKOGAWA DENKI SEISAKUSHO Co., LTD., Japan), two plastic-tank-radiators (RF1, RF2 A/T, KOYO RADIATOR Co., LTD., Japan), four $500 \mathrm{~W}$ pipe heaters, a pump circulating (FKP-1, ASONE Co., LTD., Japan), four temperature controllers (TC-3000, ASONE Co., LTD., Japan $)$ and a $160 \mathrm{~L}(41 \times 52 \times 76 \mathrm{~cm})$ water bath. In this experiment, the water temperature was $60^{-}-65^{\circ} \mathrm{C}$, and the outlet air temperature from the vinyl hose was $5-8^{\circ} \mathrm{C}$ higher than the inlet air temperature for the electric blower (Fig. 1). While partial heating, each source-sink unit was covered by a plastic bag as shown in Fig. 1.

Experiment 1: Short-term effect of altering time of nighttime heating by a partial heating system on fruit growth

Seven-year-old Satsuma mandarin trees grown in a plastic house were used. The heating was started on November 27, 2009 and the full bloom occurred on January

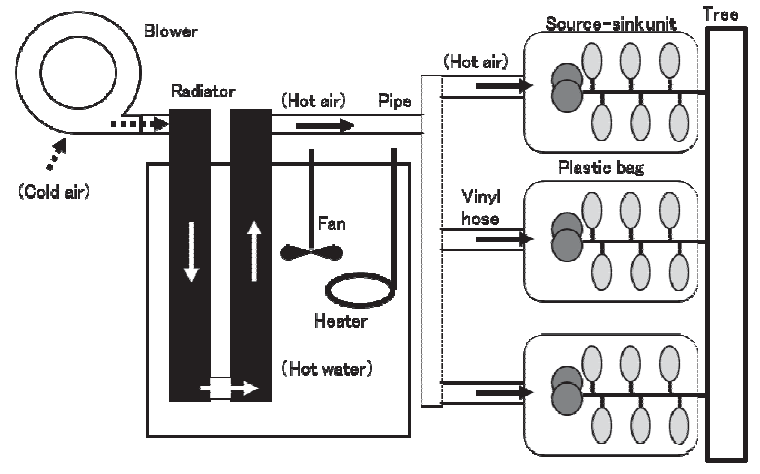

Fig. 1 A schematic drawing of the partial heating system.

5, 2010. The short-term experiment using the partial heating system was conducted at $116^{-117}$ days after full bloom (DAFB). Nighttime temperature regimes were set as EODheating, MON (Middle Of Night)-heating, and Pd (Predawn)-heating.

Experiment 2: Short-term effect of altering time of nighttime heating on ${ }^{13} \mathrm{C}$ partitioning in the sourcesink unit

Three six-year-old Satsuma mandarin trees grown in a plastic house were used. The heating was started on December 17, 2010 and the full bloom was on January 22, 2011. ${ }^{13} \mathrm{C}$ partitioning was measured by the method outlined in the previous report (Yano et al., 2012), whereas, in this study, only the leaves and stem of the source-sink unit were fed ${ }^{13} \mathrm{C}$, and fruit were not. The short-term experiment using the partial heating system (Fig. 1) was conducted at 99-105 DAFB. Nighttime temperature regimes were set as high night temperature regime $\left(\mathrm{HN}, 25^{\circ} \mathrm{C}\right.$ constant), EOD-heating, MON-heating, Pd-heating, and low night temperature regime ( $\mathrm{LN}, 17^{\circ} \mathrm{C}$ constant).

Experiment 3: Altering time of nighttime heating regimes and conventional nighttime heating regime

Nineteen-year-old Satsuma mandarin trees grown in a plastic house were used. The heating was started on December 19, 2012 and the full bloom was on January 26, 2013. During 60-90 DAFB, night temperature regimes were set as EOD-heating $\left(23^{\circ} \mathrm{C}\right.$ from $\left.1800-2200\right)$, MONheating (Middle Of Night, $23^{\circ} \mathrm{C}$ from $2200^{-0200)}$ ), and Con (Conventional nighttime heating, $20^{\circ} \mathrm{C}$ constant) (Fig. 4B), and the average temperatures (day/night) under EOD, $\mathrm{MON}$ and Con were $25.6^{\circ} \mathrm{C} / 20.5^{\circ} \mathrm{C}, 25.2^{\circ} \mathrm{C} / 19.9^{\circ} \mathrm{C}$ and $25.1^{\circ} \mathrm{C} / 20.8^{\circ} \mathrm{C}$, respectively. After $90 \mathrm{DAFB}$, the conditions were adjusted to follow the conventional practice. Soluble sugar and acid contents of fruit juice were measured with a digital refractometer (PR-101, ATAGO Co., Ltd., Japan) and by titration method, respectively. The xylem water potential at predawn was measured using pressure chamber (DKT-7000, Daiki Rika Kogyo Co., LTD., Japan).

Experiment 4: Nighttime temperature regimes determined by daily integrated solar radiation

Nine-year-old Satsuma mandarin trees grown in a plastic house were used. The heating was started on December 27, 2011 and the full bloom was January 26, 2012. The altering nighttime temperature regime by 
integrated solar radiation was as follows: if diurnal integrated solar radiation $\left(\Sigma R_{\mathrm{s}}\right)>7 \mathrm{MJ} \cdot \mathrm{m}^{-2}$, then the temperature was $23^{\circ} \mathrm{C}$ from $1800^{-} 0000$ and $17^{\circ} \mathrm{C}$ from $0000^{-0600}$; if $2 \mathrm{MJ} \cdot \mathrm{m}^{-2}<\Sigma R_{\mathrm{s}}<7 \mathrm{MJ} \cdot \mathrm{m}^{-2}$, then the temperature was $20^{\circ} \mathrm{C}$ from $1800^{-0000}$ and $17^{\circ} \mathrm{C}$ from $0000^{-0600}$; and if $\Sigma R_{\mathrm{s}}$ $<2 \mathrm{MJ} \cdot \mathrm{m}^{-2}$ then the temperature was $17^{\circ} \mathrm{C}$ constant from 1800-0600. Nighttime temperature was controlled by a temperature controller (NT-341HN, NEPON Inc., Japan) and a PAR meter (LP PAR 01, Delta OHM). Table 1 shows the patterns of nighttime temperature regime. ${ }^{13} \mathrm{C}$ partitioning was measured by the methods of previous report (Yano et al., 2012) and fruits were divided into two parts, peel: cortex, oil grand and albedo, and another: the locular membrane (LM) and juice sac (JS) according to the previous report (Yakushiji et al., 1998). Soluble sugar and acid contents of fruit juice, and xylem water potential at predawn were measured by the methods shown in experiment 3 .

\section{RESULTS}

Experiment 1: Short-term effect of altering time of nighttime heating on fruit growth

Standardized fruit growth rate $\left(G R F_{\mathrm{St}}\right)$ showed negative values from 0900 to 1700 and turned to positive values during the nighttime (Fig. 2B). At 2100, the $G R F_{\mathrm{St}}$ of the EOD-heating treatment showed the large increase than the Pd heating significantly, and at midnight the $G R F_{\mathrm{St}}$ showed similar values in all the treatments (Fig. 2B).

Experiment 2: Short-term effect of altering time of nighttime heating on ${ }^{13} \mathrm{C}$ partitioning in the sourcesink unit

Figure 3 shows the changes in temperature around the source-sink units $\left(T_{\mathrm{a}}\right)$, changes of ${ }^{13} \mathrm{C}$ allocation to the fruits $\left({ }^{13} \mathrm{C}_{\mathrm{F}}\right)$ and relationships between temperature and increased rates of ${ }^{13} \mathrm{C}_{\mathrm{F}}$ at different times. At 0600 , only high night temperature heating $\left(\mathrm{HN} ; 25^{\circ} \mathrm{C}\right.$ constant) showed a small increase of ${ }^{13} \mathrm{C}_{\mathrm{F}}$ compared to low night temperature heating (LN; $17^{\circ} \mathrm{C}$ constant) (Fig. 3B). Comparing the different nighttime heating regimes, EOD-heating (1900-2200) showed a positive linear relationship between the temperature and the increasing rate of ${ }^{13} \mathrm{C}_{\mathrm{F}}$, in contrast, MONheating (2200-0200) showed a negative relationship between those (Fig. 3C).

Experiment 3: Comparison among the altering time of nighttime heating regimes and conventional nighttime heating regime at long-term

Figure 4 shows the changes in air temperature $\left(T_{\mathrm{a}}\right)$, diurnal $T_{\mathrm{a}}$ during the treatment term (60-90 DAFB), predawn xylem water potential $\left(\Psi_{\mathrm{Xy}}\right)$, fruit volume $\left(V_{\mathrm{F}}\right)$, standardized fruit growth rate $\left(G R F_{\mathrm{st}}\right)$, soluble sugar content (SSC), and
Table 1 Patterns of nighttime temperature regime in Experiment 4.

\begin{tabular}{lccc}
\hline \multirow{2}{*}{ Regime name } & \multicolumn{3}{c}{ DAFB } \\
\cline { 2 - 4 } & $78^{-95}$ & $96^{-110}$ & $111^{-120}$ \\
\hline HN & $25^{\circ} \mathrm{C}$ & $25^{\circ} \mathrm{C}$ & $22^{\circ} \mathrm{C}$ \\
ANT-1 & $25^{\circ} \mathrm{C}$ & $\mathrm{ANT}^{\mathrm{z}}$ & $\mathrm{ANT}^{\mathrm{z}}$ \\
ANT-2 & $\mathrm{ANT}^{z}$ & $\mathrm{ANT}^{\mathrm{z}}$ & $\mathrm{ANT}^{\mathrm{z}}$ \\
LN & $17^{\circ} \mathrm{C}$ & $17^{\circ} \mathrm{C}$ & $17^{\circ} \mathrm{C}$ \\
\hline
\end{tabular}

${ }^{2}$ Altering nighttime temperature by integrated solar radiation ${ }^{y} \mathrm{HN}$ : high night temperature, ANT-1: altering nighttime temperature by integrated solar radiation at $96^{-}-120$ DAFB, ANT2: altering nighttime temperature by integrated solar radiation at $78-120$ DAFB and $\mathrm{LN}$ : low night temperature

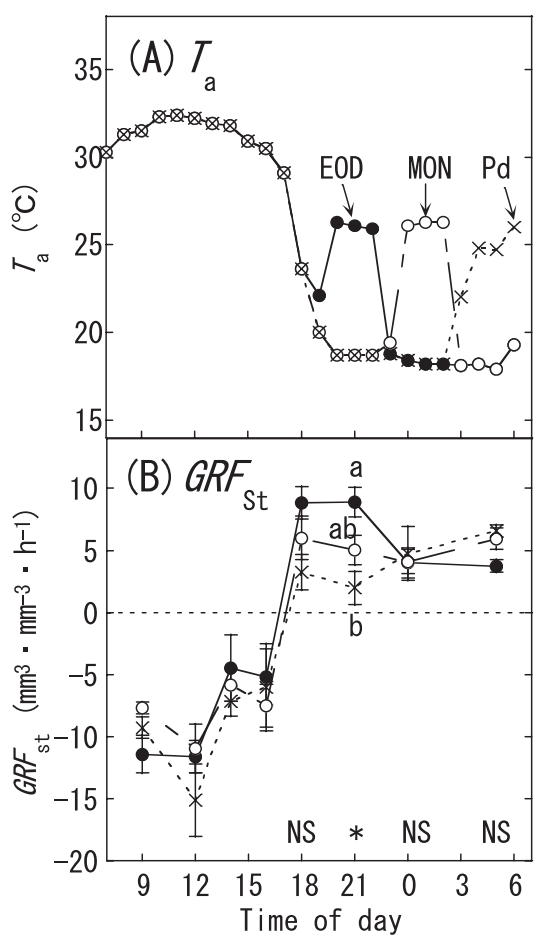

Fig. 2 Changes in the air temperatures $\left(T_{\mathrm{a}}\right)$ around the sourcesink units by the partial heating system (A) and the standardized fruit growth rate $\left(G R F_{\mathrm{St}}\right)(\mathrm{B})$ in EODheating $(\bigcirc)$, MON-heating $(\bigcirc)$ and Pd-heating $(X)$. During the nighttime, measured values indicated by scripts $\mathrm{a}$ and $\mathrm{b}$ differ significantly as determined by Tukey-Kramer's test. *: $P \leq 0.05$, NS: not significant. $\mathrm{n}=6$.

titratable acidity (TA). The $\Psi_{\mathrm{Xy}}$ showed almost identical patterns except at 140 DAFB. The difference in $\Psi_{\mathrm{Xy}}$ among treatments was within the range from 0.02 to $0.1 \mathrm{MPa}$ at 60-90 DAFB (Fig. 4C). In MON-heating, the increase of the $V_{\mathrm{F}}$ was slightly depressed during the treatment term (Fig. 4D), however, the $G R F_{\mathrm{St}}$ depressed significantly at 62 DAFB (Fig. 4E). As for the fruit quality, the SSC and the TA showed no significant differences among the treatments

Table 2 Changes in the fruit volume $\left(V_{\mathrm{F}}\right)$ and increase in $V_{\mathrm{F}}$ of each treatment that assumed size 100 at 77 DAFB during treatments in Experiment 4.

\begin{tabular}{|c|c|c|c|c|c|c|c|c|}
\hline \multirow{3}{*}{ DAFB } & \multicolumn{8}{|c|}{ Regime name } \\
\hline & \multicolumn{2}{|c|}{$\mathrm{HN}$} & \multicolumn{2}{|c|}{ ANT-1 } & \multicolumn{2}{|c|}{ ANT-2 } & \multicolumn{2}{|c|}{$\mathrm{LN}$} \\
\hline & $\mathrm{cm}^{3}$ & $(\%)$ & $\mathrm{cm}^{3}$ & $(\%)$ & $\mathrm{cm}^{3}$ & $(\%)$ & $\mathrm{cm}^{3}$ & $(\%)$ \\
\hline 77 & 23.8 & $(100)$ & 25.3 & $(100)$ & 23.9 & $(100)$ & 24.9 & $(100)$ \\
\hline 120 & 44.8 & (188) & 46.0 & (182) & 43.5 & (182) & 42.1 & (169) \\
\hline
\end{tabular}



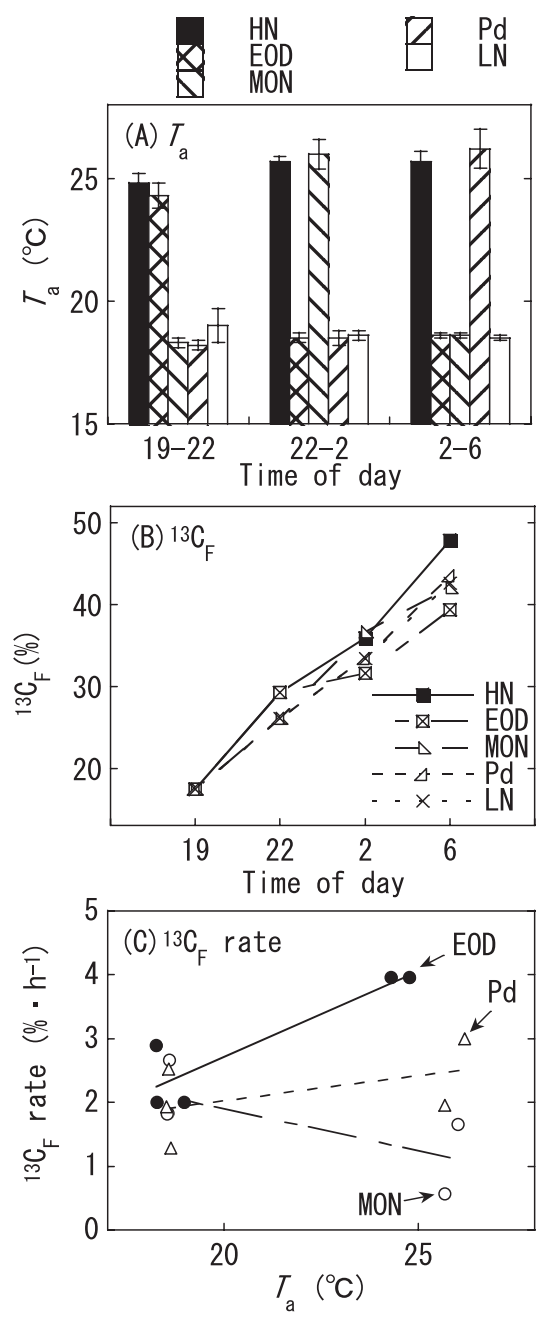

Fig. 3 Changes in the air temperatures $\left(T_{\mathrm{a}}\right)$ around source-sink units by the partial heating system $(\mathrm{A}),{ }^{13} \mathrm{C}$ allocation to the fruits in the source-sink units $\left({ }^{13} \mathrm{C}_{\mathrm{F}}\right)$ in high night temperature heating (HN), EOD-heating (EOD), MONheating $(\mathrm{MON})$, Pd-heating $(\mathrm{Pd})$, and low night temperature heating $(\mathrm{LN})(\mathrm{B})$, and increased rate of ${ }^{13} \mathrm{C}_{\mathrm{F}}$ over the different nighttime timeframes, EOD $\left(1900^{-}\right.$ 2200; $)$, MON (2200-0200; $\bigcirc)$, and Pd (0200-0600; $\triangle)(\mathrm{C})$.

(Fig. 4F).

Experiment 4: The nighttime temperature regime determined by daily integrated solar radiation

Table 2 shows the changes in the $V_{\mathrm{F}}$ during treatments. The changes in the rates of the $V_{\mathrm{F}}$ during $78-120 \mathrm{DAFB}$ in each treatment were as follows: high night temperature $(\mathrm{HN})>$ altering night temperature by the daily integrated solar radiation at $78-120$ DAFB (ANT-1) $\fallingdotseq$ altering night temperature by the daily integrated solar radiation at 91120 DAFB (ANT-2)> low night temperature (LN).

Figure $5 \mathrm{~A}$ indicates measured air temperatures throughout the treatment term. The $G R F_{\mathrm{St}}$ at $80 \mathrm{DAFB}$ showed the tendency that HN and ANT-1 were higher than the ANT-2 and LN (Fig. 5D). After $96 \mathrm{DAFB}$, the $G R F_{\mathrm{st}}$ showed similar values and lowered by day in all the treatments (Fig. 5D). A temporary positive peak of the $G R F_{\mathrm{st}}$ at $119 \mathrm{DAFB}$ was indicated, that was affected by the irrigation at $118 \mathrm{DAFB}$ and related to a slight increase
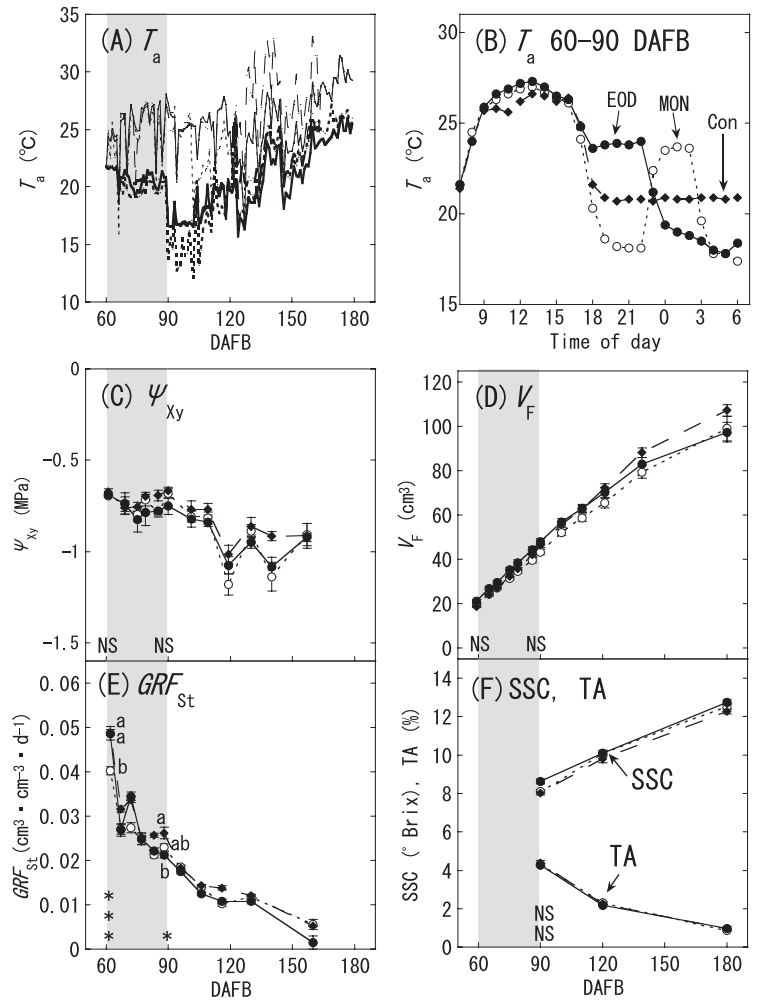

Fig. 4 Changes in air temperature $\left(T_{\mathrm{a}}\right)$ at daytime (narrow line) and nighttime (bold line) (A) in EOD-heating (EOD; solid line), MON-heating (MON; dotted line with narrow interval) and conventional nighttime heating (Con; dotted line with wide interval), $T_{\mathrm{a}}$ during the treatment term $\left(60^{-90} \mathrm{DAFB}\right)(\mathrm{B})$, predawn xylem water potential $\left(\Psi_{\mathrm{Xy}}\right)(\mathrm{C})$, fruit volume $\left(V_{\mathrm{F}}\right)(\mathrm{D})$, standardized fruit growth rate $\left(G R F_{\mathrm{st}}\right)(\mathrm{E})$, soluble sugar content (SSC), and titratable acidity (TA) (F) in EODheating (EOD; ), MON-heating (MON; $\bigcirc$ ) and conventional nighttime heating (Con; ). The graybackground shows the treatment term. At the beginning and end of treatment term, measured values indicated by scripts a and $\mathrm{b}$ differ significantly as determined by Tukey-Kramer's test. *: $P \leq 0.05$, ***: $P \leq$ 0.001 , NS: not significant. $\mathrm{n} \geq 5$.

of $\Psi_{\mathrm{xy}}$ under all the treatments (Fig. 5B and D). The $\Psi_{\mathrm{x}}$ showed almost identical patterns during the treatment term (Fig. 5 B). The changes in the SSC and the TA showed no clear differences among the treatments at 78-120 DAFB and 120-180 DAFB (Fig. 5E).

Figure 6 shows the diurnal changes of air temperature and ${ }^{13} \mathrm{C}$ partitioning in the source-sink unit at 90 and 120 DAFB. The night temperatures did not show the clear effect on ${ }^{13} \mathrm{C}$ allocation from the leaves to the fruit (the locular membrane (LM), juice sac (JS), and peel) at both 90 DAFB (Fig. 6B-C) and 120 DAFB (Fig. 6E-F). However, the fruit stage showed a different response to night temperature. At $90 \mathrm{DAFB},{ }^{13} \mathrm{C}$ assimilates in the fruit $\mathrm{LM}+\mathrm{JS}$ (parts that are eaten) tend to increase with time (Fig. 6B). In contrast, at $120 \mathrm{DAFB}$, few ${ }^{13} \mathrm{C}$ assimilates were detected in the LM+JS (Fig. 6E). 

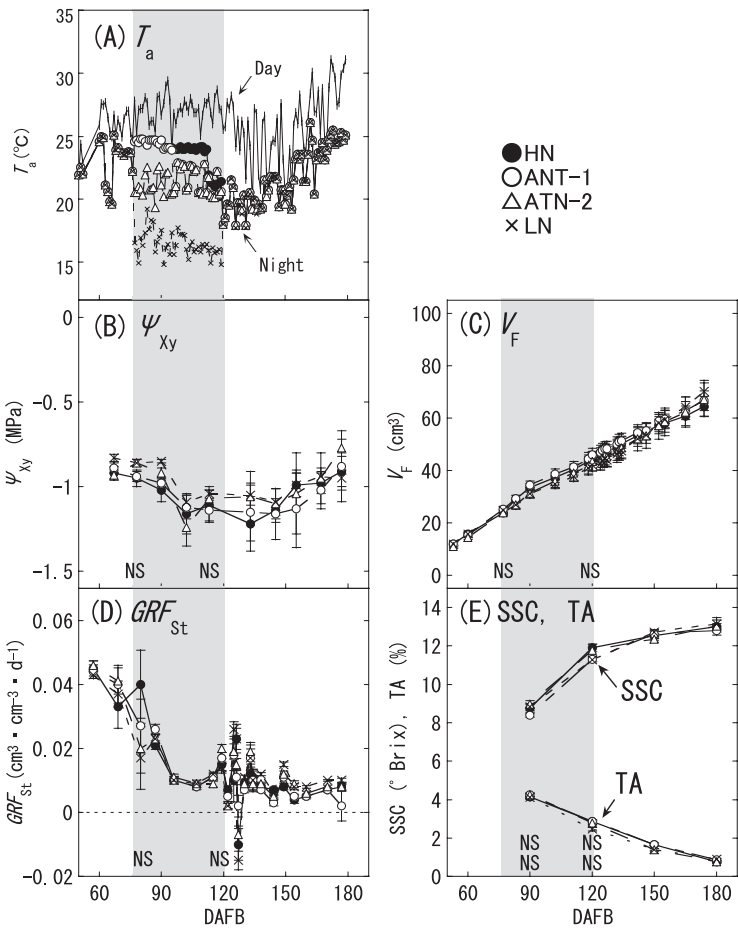

Fig. 5 Changes in air temperature $\left(T_{\mathrm{a}}\right)$ during the treatment term $(78-120 \mathrm{DAFB})(\mathrm{A})$, fruit volume $\left(V_{\mathrm{F}}\right)$, soluble sugar content (SSC) and titratable acidity (TA) (B), predawn xylem water potential $\left(\Psi_{\mathrm{xy}}\right)(\mathrm{C})$, and standardized fruit growth rate $\left(G R F_{\mathrm{St}}\right)$ in high night temperature $(\mathrm{HN} ; \mathrm{)})$, altering night temperature by solar radiation 96-120 DAFB (ANT-1; $\bigcirc$ ), altering night temperature by solar radiation $78^{-120}$ DAFB $($ ANT-2; $\triangle$ ) and low night temperature $(\mathrm{LN} ; \times)$. The gray-background shows the treatment term. At the beginning (or first measurement) and end of treatment term, treatments were compared by Tukey-Kramer's test. NS: not significant. $\mathrm{n} \geq 5$.

\section{DISCUSSION}

In this study, two types of energy-saving night temperature regimes were applied. One type was the altering time of nighttime heating which including end of day (EOD)-heating, researched in experiment 1,2, and 3, and another type was nighttime temperature regime determined by solar radiation, researched in experiment 4 , respectively. On the whole, the nighttime temperature regimes both altering time of that and which determined by solar radiation were not superior to the conventional night temperature regime, in the other words, the integrated effects of different night temperature regime on fruit growth and quality were negligible in Satsuma mandarin.

In the former type, the EOD-heating temporally activated the fruit growth (Fig. 2) and accelerated the ${ }^{13} \mathrm{C}$ allocation from leaf to fruit (Fig. 3) through short term (hours) researches by the partial heating, however, comparing to the conventional heating as $20^{\circ} \mathrm{C}$ constant in nighttime by the whole tree heating during 60-90 DAFB, no superiority was observed both in the fruit volume increase and fruit quality (Fig. 4). In addition, the MON-heating showed the depression of fruit growth (Fig. 4E), thus, at least this term

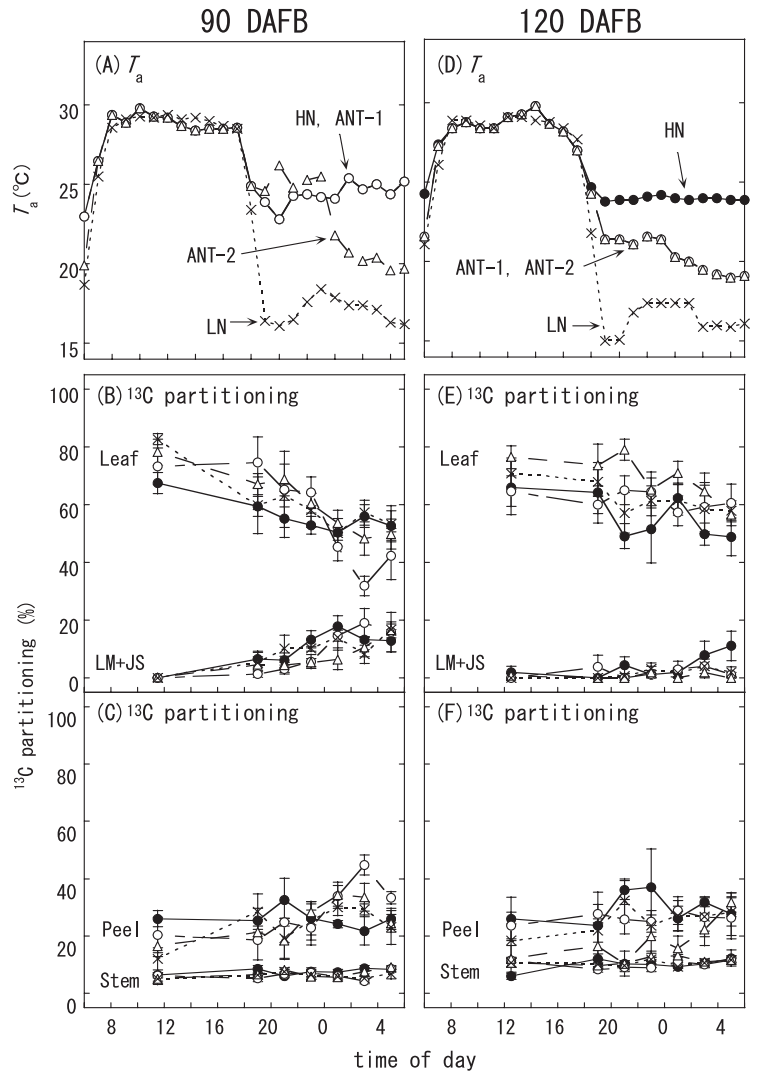

Fig. 6 Diurnal changes in air temperature $\left(T_{\mathrm{a}}\right)(\mathrm{A}$ and $\mathrm{D}),{ }^{13} \mathrm{C}$ partitioning in the source-sink unit $(\mathrm{B}-\mathrm{C}$ and $\mathrm{E}-\mathrm{F})$ at 90 and 120 DAFB in high night temperature ( $\mathrm{HN}$; ), altering night temperature by solar radiation 96-120 DAFB (ANT-1; $\bigcirc$ ), altering night temperature by solar radiation $78^{-120}$ DAFB (ANT-2; $\triangle$ ), and low night temperature $(\mathrm{LN} ; \times)$. LM + JS indicate locular membran + juice sac-in panels $\mathrm{B}$ and $\mathrm{E}$.

should not be lower than $20^{\circ} \mathrm{C}$. In the latter type, only low night temperature regime such as $17^{\circ} \mathrm{C}$ at 80DAFB affected the depression of fruit growth whereas that did not affect the fruit quality (Fig. 5C-D). These results indicated that the EOD-heating and nighttime temperature regime which depend on solar radiation were not superior to the conventional night temperature regime in Satsuma mandarin.

It has been suggested that temperature determines fruit quality in the Satsuma mandarin, low night temperatures as $8^{-} 15^{\circ} \mathrm{C}$ delayed the decrease of the juice-acid and increase of the juice-sugar contents (Kurihara, 1969, 1971; Nii et al., 1970; Utsunomiya et al., 1982; Inoue and Chien, 1988), but in our results, fruit sugar and acid content did not show apparent increases or decreases when exposed to low nighttime temperatures as $17^{\circ} \mathrm{C}$ (Fig 5E). In the previous reports, the experiments were conducted at growth stages II-III (from cell enlargement period to maturation period; Kikuchi et al., 1964) in environments that resembled autumn and winter conditions in the field culture of Satsuma mandarins. In addition, the delayed decrease in the juice-acid content is accompanied by a depression in fruit volume enlargement (Kurihara, 1969, 1971; Utsunomiya et al., 1982; Inoue and Chien, 1988). In Satsuma mandarins grown in a plastic house with heating which is harvested fruit at summer, the nighttime air 
temperature was considered to be within the suitable range for fruit growth $\left(20^{-} 25^{\circ} \mathrm{C}\right)$ at stage III (Yano et al., 2014). In this case, fruit with excessive acid content is rarely produced as long as water is managed precisely. The acid content of the fruit may be determined by both the acid metabolism of the fruit, especially the tricarboxylic acid cycle, and the physiological volume enlargement of the fruit during stages II-III.

Satsuma mandarins grown in a plastic house with heating which produce high quality fruit are usually under chronic water stress, in a previous report, predawn leaf water potentials averaged $-0.60 \mathrm{MPa}$ for moderately drought stressed, and $-1.00 \mathrm{MPa}$ for severely water stressed (Yakushiji et al., 1998). Numerous short-term studies have shown a constant increase in fruit volume during the daytime in tomatoes (Pearce et al., 1993; Araki et al., 1997, 2001; Kitano et al., 1998a, 1998b; Kitano and Araki, 2001). In tomato, under water deficit conditions, the daytime temporary decrease in the fruit volume due to sap back flow was shown (Araki et al., 1998, 2004). In Satsuma mandarins under moderate water stress, temporary decrease in fruit volume often occurred during sunny daytime and steep increase in the fruit volume occurred from late afternoon to beginning of nighttime (Yano et al., 2012, 2013).

The source-sink relationship might be altered with the fruit stage. In this study, ${ }^{13} \mathrm{C}$ allocation to the fruit (locular membrane and juice sac) was detected at 90 DAFB, but was nearly absent at $120 \mathrm{DAFB}$, regardless of high night temperature at both days (Fig. 6). From this result, the temperature required for carbon translocation from the leaf to the fruit might be greater in the fruits before 90 DAFB than after $90 \mathrm{DAFB}$, that demonstrates the effectiveness of the energy-saving night temperature regime from $90^{-120}$ DAFB. In addition, the increases of ${ }^{13} \mathrm{C}$ allocation to fruits in the daytime were detected at neither 90 DAFB nor 120 DAFB regardless of temperatures as high as $27-28^{\circ} \mathrm{C}$ (Fig. 6). It will be necessary to clarify why the increase of ${ }^{13} \mathrm{C}$ allocation to fruits was not promoted in spite of the high day temperature, for example, the reason might be the difference of the fruit stage and/or severe water status.

\section{CONCLUSION}

The nighttime temperature regimes both altering time of that and which determined by solar radiation were not superior to the conventional night temperature regime. A possible energy-saving temperature regime for Satsuma mandarins grown in a plastic house with heating has been developed. Firstly, at 60-90 DAFB, it is necessary to control $25^{\circ} \mathrm{C}$ in the daytime (Yano et al., 2014) and not to be lower than $20^{\circ} \mathrm{C}$ at night (Fig. 4E). Secondly, at 90-120 DAFB, $17^{\circ} \mathrm{C}$ might be a sufficiently high nighttime temperature for high quality fruit production (Fig. 5E). This progressive temperature regime would show apparent energy-saving effects compared to the conventional nighttime regime of $23^{-}-25^{\circ} \mathrm{C}$ from $50^{-}-120$ DAFB.

This research was supported by Research and Development
Projects for Application in Promoting New Policy of Agriculture, Forestry and Fisheries (No. 21061) from the Ministry of Agriculture, Forestry and Fisheries of Japan, and by Grants-in-Aid for Scientific Research (No. 2338015) from the Japan Society for Promotion of Science.

\section{REFERENCES}

Araki, T., Eguchi, T., Wajima, T., Yoshida, S., Kitano, M. 2004. Dynamic analysis of growth, water balance and sap fluxes through phloem and xylem in a tomato fruit: Short-term effect of water stress. Environ. Control Biol. 42: 225-240.

Araki, T., Kitano, M., Eguchi, H. 1997. Respiration, sap flux, water balance and expansive growth in tomato fruit. Biotronics 26: 95-102.

Araki, T., Kitano, M., Hamakoga, M., Eguchi, H. 1998. Analysis of growth, water balance and respiration of tomato fruits under water deficit by using a multiple chamber system. Biotronics 27: 61-68.

Araki, T., Kitano, M., Okano, K., Yoshida, S., Eguchi, T. 2001. Environmental effects on dynamics of fruit growth and photoassimilate translocation in tomato plants III. Effect of salt stress. (in Japanese text with English summary) Environ. Control Biol. 39: 53-58.

Bonaminio, V. P., Larson, R. A. 1980. Influence of reduced night temperatures on growth and flowering of 'May Shoesmith' chrysanthemums. J. Am. Soc. Hortic. Sci. 105: 911.

Challa, H., Brouwer, P. 1985. Growth of young cucumber plants under different diurnal temperature patterns. Acta Hortic. 174: 211-217.

Douzono, M., Hisamatsu, T., Ohmiya, A., Ichimura, K., Shibata, M. 2012. Effect of end-of-day-heating treatment in low growth-temperature environment on growth and flowering in spray-type Chrysanthemum. (in Japanese text with English summary) Hortic. Res. 11: 505-513.

Douzono, M., Hisamatsu, T., Ohmiya, A., Shibata, M. 2010. Acceleration of flowering response by short-term heat treatment at the beginning of the dark period in African marigold. (in Japanese text with English summary) J. Sci. High Technol. Agric. 22: 8-14.

Heuvelink, E. 1995. Effect of temperature on biomass allocation in tomato (Lycopersicon esculentum). Physiol. Plant. 94: 447-452.

Inoue, H., Chien, C. 1988. Effects of temperature on fruit growth and quality after the period of physiological fruit drops in Satsuma mandarin. (in Japanese text with English summary) Tech. Bull. Fac. Agric., Kagawa Univ. 40: 31-36.

Kikuchi, T., Kadoya, K., Kuraoka, T. 1964. Morphological studies on the development of citrus fruits. II. Differences in certain species and varieties. (in Japanese text with English summary) J. Hortic. Sci. 33: 8-12.

Kitano, M., Araki, T. 2001. Environmental effects on dynamics of fruit growth and photoassimilate translocation in tomato plants II. Analysis of phloem sap and xylem sap fluxes and fruit water balance. (in Japanese text with English summary) Environ. Control Biol. 39: 43-51.

Kitano, M., Araki, T., Eguchi, H. 1998a. Environmental effects on dynamics of fruit growth and photoassimilate translocation in tomato plants I. Effects of irradiation and day/night temperature. (in Japanese text with English summary) Environ. Control Biol. 36: 225-240.

Kitano, M., Araki, T., Eguchi, H. 1998b. Temperature dependence of postphloem transport regulated by respiration in tomato fruits. Biotronics 27: 33-39. 
Kurihara, A. 1969. Fruit growth of Satsuma orange under controlled condition I. Effect of preharvest temperature on fruit growth, colar development, and fruit quality in Satsuma orange. (in Japanese text with English summary) Bull. Hortic. Res. Sta., Jpn., Ser. A 8: 15-30.

Kurihara, A. 1971. Fruit growth of Satsuma orange under controlled condition II. Effect of night temperature in the fall on fruit growth, colar development, and fruit quality of Satsuma orange. (in Japanese text with English summary) Bull. Hortic. Res. Sta., Jpn., Ser. A 10: 29-37.

Langhans, R. W., Wolf, M., Albright, L. D. 1981. Use of average night temperatures for plant growth for potential energy savings. Acta Hortic. 115: 31-37.

Nii, N., Harada, K., Kadowaki, K. 1970. Effect of temperature on the fruit growth and quality of Satsuma oranges. (in Japanese text with English summary) J. Hortic. Sci. 39: 309317.

Parups, E. V. 1978. Chrysanthemum growth at cool night temperature. J. Am. Soc. Hortic. Sci. 103: 839-842.

Pearce, B. D., Grange, R. I., Hardwick, K. 1993. The growth of young tomato fruit. I. Effects of temperature and irradiance on fruit grown in controlled environments. J. Hortic. Sci. 68: 111.

Utsunomiya, N., Yamada, H., Kataoka, I., Tomana, T. 1982. The effect of fruit temperatures on the maturation of Satsuma mandarin (Citrus unshiu Marc.) fruits. (in Japanese text with English summary) J. Jpn. Soc. Hortic. Sci. 51: 135-141.

Yakushiji, H., Morinaga, K., Nonami, H. 1998. Sugar accumu- lation and partitioning in Satsuma mandarin tree tissues and fruit in response to drought stress. J. Am. Soc. Hortic. Sci. 123: 719-726.

Yano, T., Matsubara, K., Shimooka, M., Tamanoi, A., Narahara, M., Kawano, M., Ito, S., Setoyama, S., Yasunaga, E., Araki, T., Kitano, M. 2014. Energy saving night temperature regime for Satsuma mandarins (Citrus unshiu Marc.) grown in a plastic house with heating. I Effect of temperature and water condition on fruit growth and quality. Environ. Control Biol. 52: $161-166$.

Yano, T., Ohara, M., Matsubara, K., Tamanoi, A., Araki, T., Setoyama, S., Yasunaga, E., Kitano, M. 2013. Effect of light condition on water and carbon balance in Satsuma mandarin (Citrus unshiu Marc.) fruit. Environ. Control Biol. 51: 49-56.

Yano, T., Kawano, T., Ohara, M., Sato, Y., Kotegawa, R., Kagawa., H, Setoyama, S., Yokota, N., Nomiyama., R., Araki, T., Yasunaga, E., Eguchi, T., Kitano, M. 2012. Water and carbon balance in developing fruit of Satsuma mandarin (Citrus unshiu Marc.). Environ. Control Biol. 50: 189-198.

Yoshioka, H., Takahashi, K. 1981. Studies on the translocation and accumulation of photosynthates in fruit vegetables. V Translocation of photosynthates in a day, and effect of light conditions and night temperature on translocation and distribution of ${ }^{14} \mathrm{C}$-photosynthates in tomato plants. (in Japanese text with English summary) Bull. Veg. Orn. Crops Res. Stn. Jpn. Ser. A 9: 63-81. 